\title{
A Quantitative Study of Muscle Fiber Survival and Regeneration in Normal, Predenervated, and Marcaine-Treated Free Muscle Grafts in the Rat
}

\author{
Bruce M. Carlson ${ }^{2}$ \\ Department of Anatomy, University of Michigan, Ann Arbor, Michigan 48109 \\ Received February 12, 1976; revision received April 30, 1976
}

\begin{abstract}
Free grafts were performed on the rat extensor digitorum longus muscle after no pretreatment, 14-day predenervation, or two or one preinjections of Marcaine. Numbers of surviving muscle fibers were counted in 4-day grafts, and the total number of muscle fibers was counted in 60-day grafts. Mean numbers of surviving muscle fibers in 4-day grafts were 132 for untreated muscles, 1166 for predenervated muscles, and eight and two for muscles treated with two and one Marcaine injections, respectively. In all four groups, the numbers of muscle fibers in 60-day grafts did not differ significantly from the mean number of muscle fibers (3880) in the normal extensor digitorum longus. It was concluded that most of the muscle fibers found in a mature free graft are newly regenerated rather than surviving original muscle fibers.
\end{abstract}

\section{INTRODUCTION}

The successful free autografting of muscles has only recently been accomplished. Studitsky and Bosova $(2,15)$ reported that after preliminary denervation, entire gastrocnemius muscles in rats could be freely grafted, whereas grafts of muscles that had not been predenervated were unsuccessful and were ultimately replaced by a band of connective tissue. Independently, Thompson $(16,17)$ reported the successful free grafting of muscles in both dogs and humans, again after a period of denervation of the donor muscle prior to grafting.

Since these original reports, the free grafting technique has come into increasing use for both experimental laboratory research and clinical application, the latter primarily by plastic surgeons. Nevertheless, the mech-

${ }^{1}$ Supported by grants from the Muscular Dystrophy Association and National Institutes of Health (NS 13116-01). 
anism accounting for the success of free muscle grafts is not entirely clear. Thompson $(16,18)$ assumes that preliminary denervation alters the metabolic properties of muscle fibers in a manner allowing them to survive intact for the first few days after grafting, during which, according to this interpretation, essentially all of the original muscle fibers survive. Other mechanisms, such as regeneration, are not considered necessary. The survival of original muscle fibers is the mechanism accepted by some of the other plastic surgeons $(8,9)$, but a recent report $(14)$ has recognized the existence of both survival and regeneration.

In contrast to the opinion that survival of original muscle fibers is the primary mechanism accounting for the success of free grafts, other investigators $(4,5,15,20,21)$, although not denying some degree of survival of original muscle fibers, have postulated that the bulk of a long-term free muscle graft is formed by newly regenerating muscle fibers.

The present study was undertaken to provide quantitative data that make it possible to assess the relative contributions of surviving and regenerating muscle fibers to free grafts of the extensor digitorum longus muscle in the rat. The experimental strategy consisted of comparing the numbers of differentiated muscle fibers found in long-term (60 day) free extensor digitorum longus grafts with the numbers of morphologically intact and histologically viable-appearing muscle fibers in 4-day free grafts of normal, predenervated and Marcaine-treated muscles. Any difference between the numbers of viable-appearing muscle fibers in 4-day and 60-day grafts was assumed to be derived from regenerating muscle fibers.

\section{MATERIALS AND METHODS}

This study was conducted on 60 male Sprague-Dawley rats weighing from 175 to $200 \mathrm{~g}$. For operations and autopsies all animals were under ether anesthesia. All free grafts of the extensor digitorum longus muscle were carried out in the manner previously reported $(5,6)$. The muscle was completely removed from its own bed and then grafted back into either its own bed (orthotopic graft) or, when predenervated muscles were used, into the bed of the contralateral extensor digitorum longus. Previous operations on several hundred rats have shown that ipsilateral or contralateral grafts can be regarded as equivalent. The grafts were fixed at either end of the tendons of origin and insertion of the extensor digitorum longus. The stump of the motor nerve was allowed to remain free, alongside the graft. The transplanted muscle had no connections with the vascular system of the host.

Treatment of Grafts. Muscles of one group were orthotopically grafted without pretreatment, and are referred to as normal grafts. In a second group, one leg of each rat was denervated for 14 days by a high sciatic 
neurotomy. The 14-day predenervated extensor digitorum longus was then grafted in place of the contralateral normal extensor digitorum longus.

Muscles in the remaining two groups were treated with Marcaine. HallCraggs $(10,11)$ has described a method of obtaining the rapid degeneration and regeneration of the tibialis anterior muscle in the rat following multiple injections of the muscle with a solution of Marcaine. In this laboratory complete degeneration of muscle fibers could not be obtained in 40 nontransplanted extensor digitorum longus muscles injected with Marcaine under direct surgical exposure, but combined with transplantation, Marcaine injection proved to be an effective means of eliminating virtually all original muscle fibers in the extensor digitorum longus.

The injection solution consisted of $0.75 \%$ Marcaine $\mathrm{HCl}$ (Winthrop) in $0.9 \%$ saline to which 30 units (International unit = USP unit) of hyaluronidase-300 (beef testes-ICN Pharmaceuticals) per milliliter of Marcaine was added.

In one group (Marcaine preinjection), the distal part of the extensor digitorum longus muscle was surgically exposed and the muscle was injected with as much of the Marcaine solution as it would hold (about $100 \mu \mathrm{l}$ ). The tissues over the exposed portion of the muscle were sutured. Two days later, the preinjected muscle was removed and again injected with as much Marcaine as it could hold. It was then soaked $10 \mathrm{~min}$ in the Marcaine solution to destroy as many peripheral muscle fibers as possible. Muscles soaked $10 \mathrm{~min}$ in saline did not differ in their reactions to free grafting from muscles transplanted immediately after removal. Because of damage to surrounding muscles caused by in situ injections of Marcaine, the treated muscles were grafted in place of the contralateral extensor digitorum longus muscles.

In the other Marcaine group (Marcaine injection), treatment of the muscles was the same as that reported above except that the only exposure of the muscles to Marcaine was an injection and soaking for $10 \mathrm{~min}$ at the time of grafting.

Analysis of Grafts. For each group, grafts were removed from the limbs 4 and 60 days after grafting. In addition, eight normal extensor digitorum longus muscles were examined as controls. All muscles were fixed in Bouin's solution at resting length, cross-sectioned at $7 \mu \mathrm{m}$ and stained with Ehrlich's hematoxylin and eosin. For counting, muscle cross sections were projected onto a large paper and the outline of fascicles and groups of fibers were drawn. After this, total counts of individual muscle fibers could be accurately made through a microscope. Counts made in this fashion were repeatable within a range of 0.2 to $2.0 \%$.

Sixty days was chosen as a long-term period for analyzing grafts because by that time in the rat the transplants are stable with respect to 
TABLE 1

Numbers of Muscle Fibers in Short- and Long-Term Free Ga afts of the Rat Extensor Digitorum Longus Muscles after Various Treatments

\begin{tabular}{lrrrrc}
\hline Treatment of graft & $\begin{array}{c}\text { Short-term } \\
(4 \text { day) }\end{array}$ & $\begin{array}{c}\text { Number of } \\
\text { Muscles }\end{array}$ & $\begin{array}{c}\text { Long-term } \\
(60 \text { day })\end{array}$ & $\begin{array}{c}\text { Number of } \\
\text { Muscles }\end{array}$ \\
\hline $\begin{array}{l}\text { No pretreatment } \\
\text { 14-day predenervation }\end{array}$ & $132.0 \pm 140.1^{a}$ & $(4)$ & $3824.3 \pm 571.1$ & $(3)$ \\
$\begin{array}{l}\text { Marcaine preinjection } \\
\quad(-2 \text { and 0 days) }\end{array}$ & $8.2 \pm 20.2$ & $(12)$ & $4071.0 \pm 596.2$ & $(6)$ \\
$\begin{array}{c}\text { Marcaine injection } \\
\text { (0 days) }\end{array}$ & $2.2 \pm 5.8$ & $(13)$ & $3508.6 \pm 419.7$ & $(4)$ \\
\hline
\end{tabular}

${ }^{a}$ Standard deviation.

morphological, histochemical, and contractile properties $(5,6)$. The 4-day period after grafting was chosen for counts of maximum numbers of surviving muscle fibers because by that time in the extensor digitorum longus there is a well defined separation between the peripheral surviving muscle fibers and the degenerating original muscle fibers in the center of the graft. Between them is a zone of early muscle regeneration containing no intact original muscle fibers (Fig. 1).

The counts of surviving muscle fibers in 4-day grafts represent the maximum possible number, because one can not say with assurance that all these muscle fibers would continue to survive. However, by 4 days the peripheral part of a graft has become revascularized, and there is little reason to suppose that a large proportion of the intact original muscle fibers in the periphery would not continute to survive. By the end of the first week, it is often not possible to distinguish between regenerating muscle fibers and surviving muscle fibers, particularly if the graft has been predenervated.

In 60-day grafts, no way has been found to distinguish between surviving original muscle fibers and regenerating muscle fibers. One can roughly calculate that the difference between the mean total number of surviving muscle fibers in 60-day grafts and the mean number of surviving muscle fibers in 4-day grafts represents the contribution made to the grafts by regenerating muscle fibers. It is not possible to count the number of regenerating muscle fibers in a graft directly because of asynchrony in their course of differentiation during the first week or two. Because of their radial gradient of maturation, resembling that seen in a regenerated minced muscle (3), regenerating muscle fibers in the peripheral part of a graft have become cross-striated whereas regeneration in the center of the grafts is still in the myoblastic or early myotube phase. 


\section{RESULTS}

The intact extensor digitorum longus muscle in eight rats of the size used for grafting contained a mean of $3880 \pm 575$ (SD) muscle fibers in cross section. In free grafts of normal, untreated muscle, only about $3 \%$ of the original muscle fibers survived at 4 days after grafting (Table 1). These histologically viable-appearing muscle fibers were typically located in scattered groups along the periphery of the graft (Fig. 1), seldom more than two or three muscle-fiber layers away from the periphery.

Predenervated muscle grafts possessed a significantly greater number of surviving muscle fibers $(\bar{X}=1166$, or $30 \%$ of the normal number of muscle fibers) than did normal grafts (Table 1). The surviving muscle fibers were found in a relatively thick layer that encircled the peripheral area of the muscle (Fig. 2), and in some grafts, isolated healthy-looking muscle fibers could be found scattered throughout much of the central

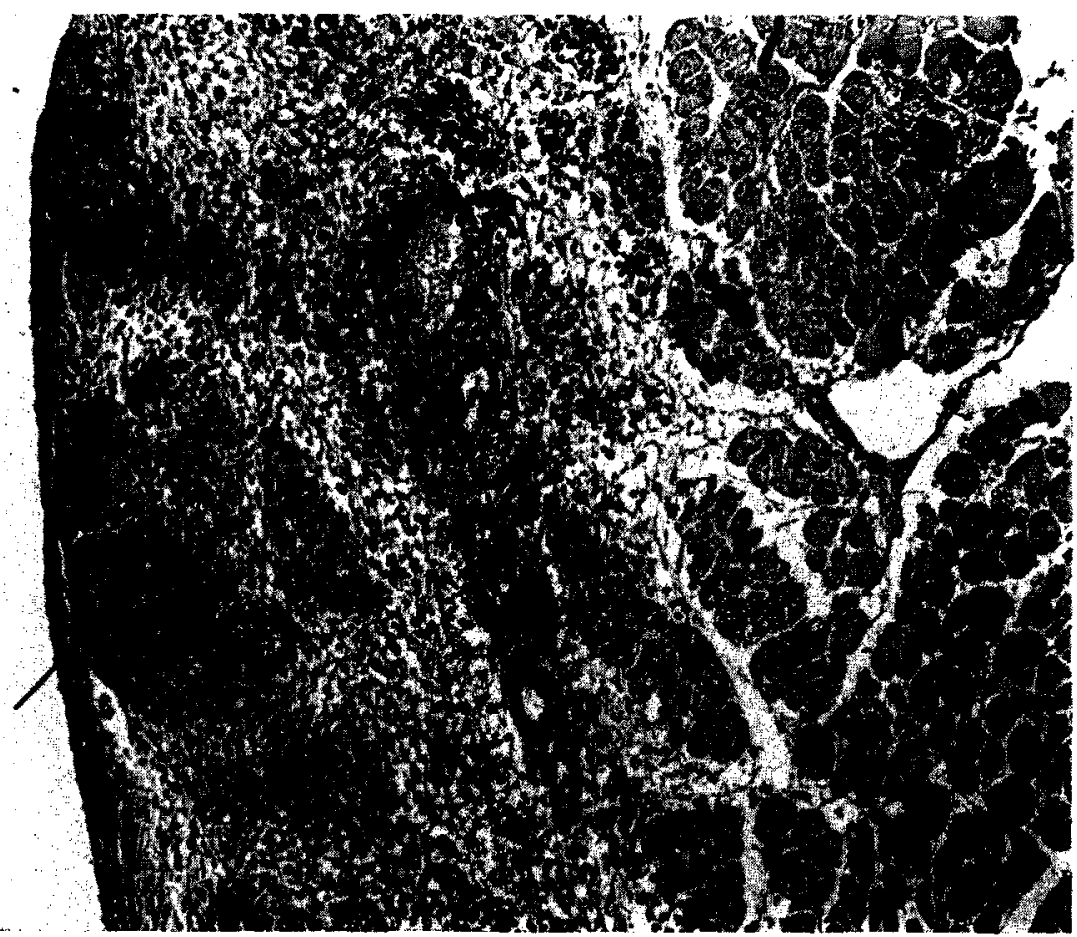

FIc. 1. Peripheral region from a 4-day graft of normal muscle. This graft had 90 surviving muscle fibers scattered throughout the periphery. The figure shows the distinction between surviving original muscle fibers at the periphery (arrow) and degenerating muscle fibers at the center (right). A zone of early regenerative activity, containing no intact original muscle fibers, separates the peripheral from the central area. Hematoxylin and eosin. $\times 124$. 
region of the graft, after the remainder of the muscle fibers had degenerated. The surviving muscle fibers were quite thin, having been denervated for 18 days ( 14 days before and 4 days after grafting).

In both groups of Marcaine-treated grafts, surviving muscle fibers were effectually eliminated. Among the 12 short-term grafts of the Marcaine preinjection series, eight possessed no intact muscle fibers, and in the zero-day injection group, nine of 13 grafts did not contain any intact muscle fibers.

Except for virtual absence of peripheral surviving muscle fibers, the overall histological appearance of Marcaine-treated muscles was similar to that of the normal and predenervated grafts (Figs. 3,4). The central ischemic muscle fibers in both Marcaine groups displayed a greater degree of fragmentation before they were attacked by macrophages than was the case in grafts of normal muscle (Fig. 5). Occasionally in both the Marcaine groups and in predenervated grafts, all the centrally located original muscle fibers had degenerated by 4 days.

The 60-day grafts of all groups possessed mean numbers of muscle

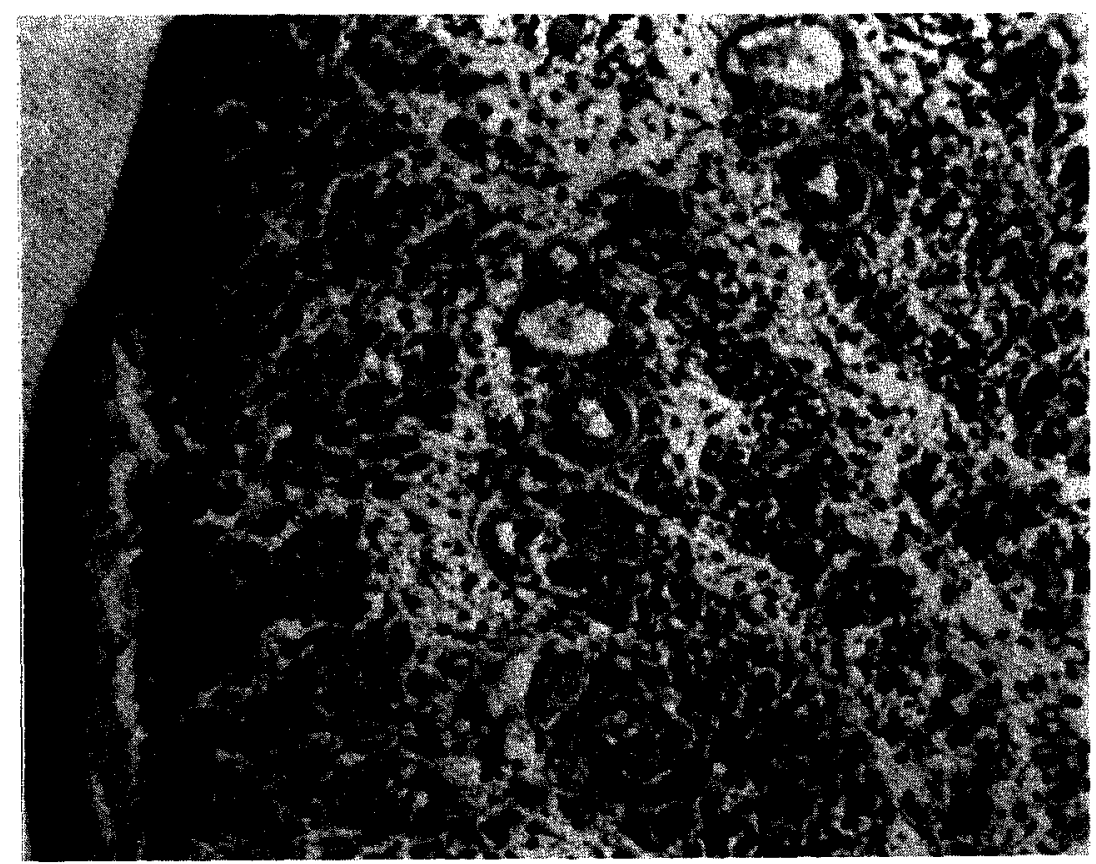

Fic. 2. Peripheral region from a 4-day graft of 14-day predenervated muscle. This graft had 1485 surviving muscle fibers. Surviving muscle fibers, thin due to their prior denervation, occupy much of the left side of this figure. At the right, occasional surviving muscle fibers are scattered among the degeneratcd muscle fibers. Hematoxylin and eosin. $\times 162$. 


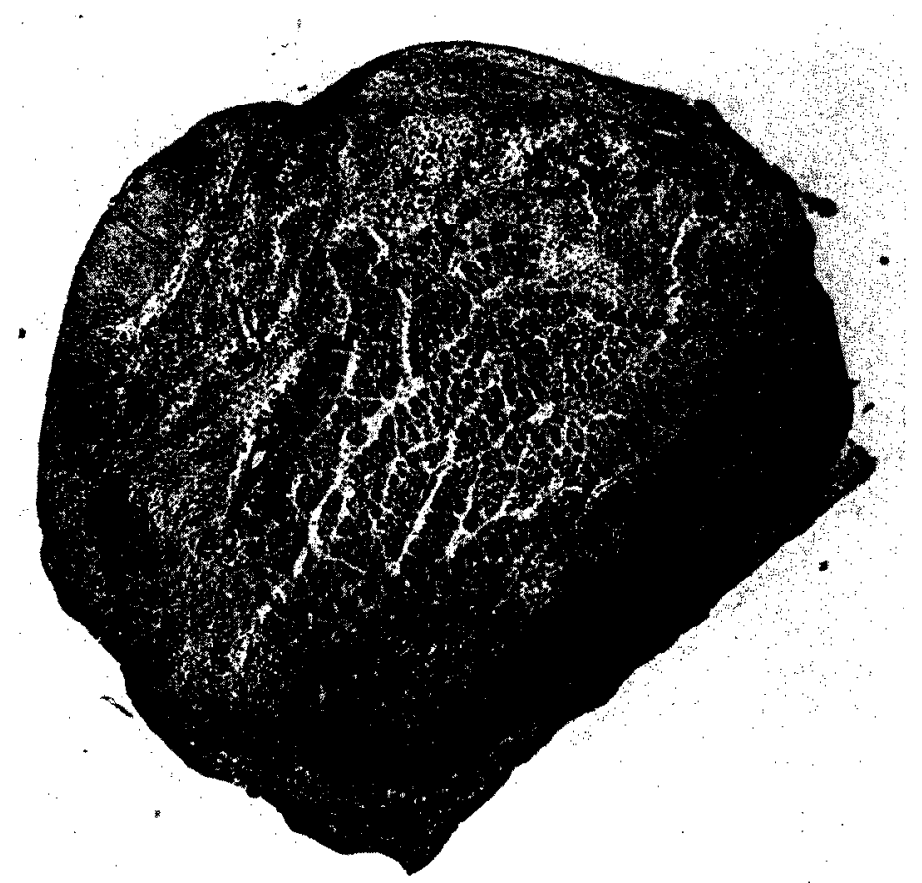

FIG. 3. Four-day graft of muscle given two preinjections of Marcaine. It contained four surviving muscle fibers in the periphery and a large central region (within dashed line) of degenerating original muscle fibers. Hematoxylin and eosin. $\times 30$.

fibers that did differ significantly from the values of normal muscles (Table 1). Histologically, it was not possible to distinguish between longterm grafts of any of the groups. The appearance of the 60-day muscle graft (Fig. 6) was the same as that described previously (5). Muscle spindles were found in cross sections of grafts in all groups, but not in all grafts. The techniques of analysis do not allow one to make any accuratc quantitative statements about muscle spindles.

\section{DISCUSSION}

This study demonstrates that with different pretreatments, the number of muscle fibers surviving the early days after the free grafting of a muscle varies considerably. Whereas only about $3 \%$ of the muscle fibers in a graft of normal muscle remain intact by the fourth day after grafting, ten times that number of healthy-appearing muscle fibers can be found in a muscle that has been denervated 14 days prior to grafting. This finding, indeed, lends some credence to the working hypothesis of Thompson (16, 18) that denervation in some way alters the metabolism of muscle fibers, enabling them to withstand the unfavorable metabolic environment im- 


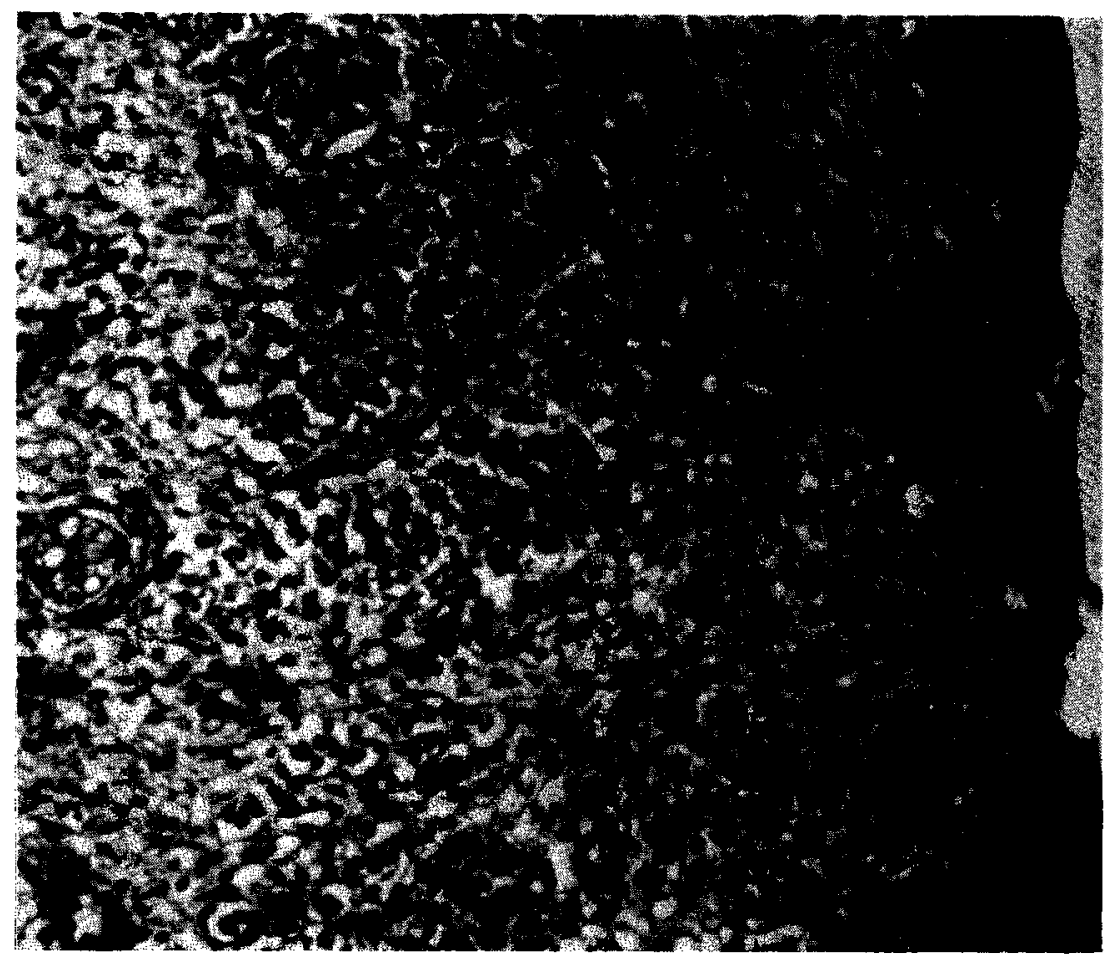

FIG. 4. Higher power view of peripheral region from the graft shown in Fig. 3. Early myotubes are seen in cross section around the periphery (right). Nearer the center of the graft (left) complete sarcolysis of the degenerated original muscle fibers has ozcurred. Hematoxylin and eosin. $\times 190$.

posed on an early muscle graft. Factors accounting for the increased survival are presently obscure, but in addition to metabolic adaptation, one must also take into account the decrease in size (diameter) of both the entire denervated muscle and the muscle fibers within it. Possibly diffusion of oxygen and needed substrates is facilitated by factors inherent to the denervated muscle, or perhaps revascularization itself may rescue a larger number of peripheral muscle fibers than is the case in a normal muscle graft.

Nevertheless, it is clear that even in a predenervated graft, survival of original muscle fibers accounts for a relatively small fraction of the muscle fibers that eventually make up the mature graft. During the first week or two after grafting, surviving muscle fibers are important components of denervated grafts from both the morphological (5) and functional (6) standpoint, but after this time, the greater mass of regenerating muscle fibers becomes the dominant feature of the graft. During the first few days after grafting, predenervated rat extensor digitorum longus muscles 
maintain a low degree of contractility, due to their surviving muscle fibers, whereas grafts of normal muscle have for the most part lost the ability to contract (6). In addition to differences in absolute numbers, the muscle fibers in normal grafts undergo a pronounced temporary drop in resting membrane potential during the first few days after grafting (19).

The overall histological pattern, seen in early grafts of the rat extensor digitorum muscle (6), is similar in most respects to that described in grafts of cat muscle by Schiaffino et al. (14). In both normal and predenervated grafts, a peripheral (outer) zone of original muscle fibers is certainly seen. A central (inner) zone of original muscle fibers in a state of ischemic necrosis is also present. In the rat, the area between the central and peripheral zones (middle zone) contains completely degenerated muscle fibers, with regenerating muscle cells forming inside their basement membranes. As the central zone shrinks, the middle zone correspondingly expands centripetally to occupy the area that formerly contained the original muscle fibers of the central zone. Because of the progressive

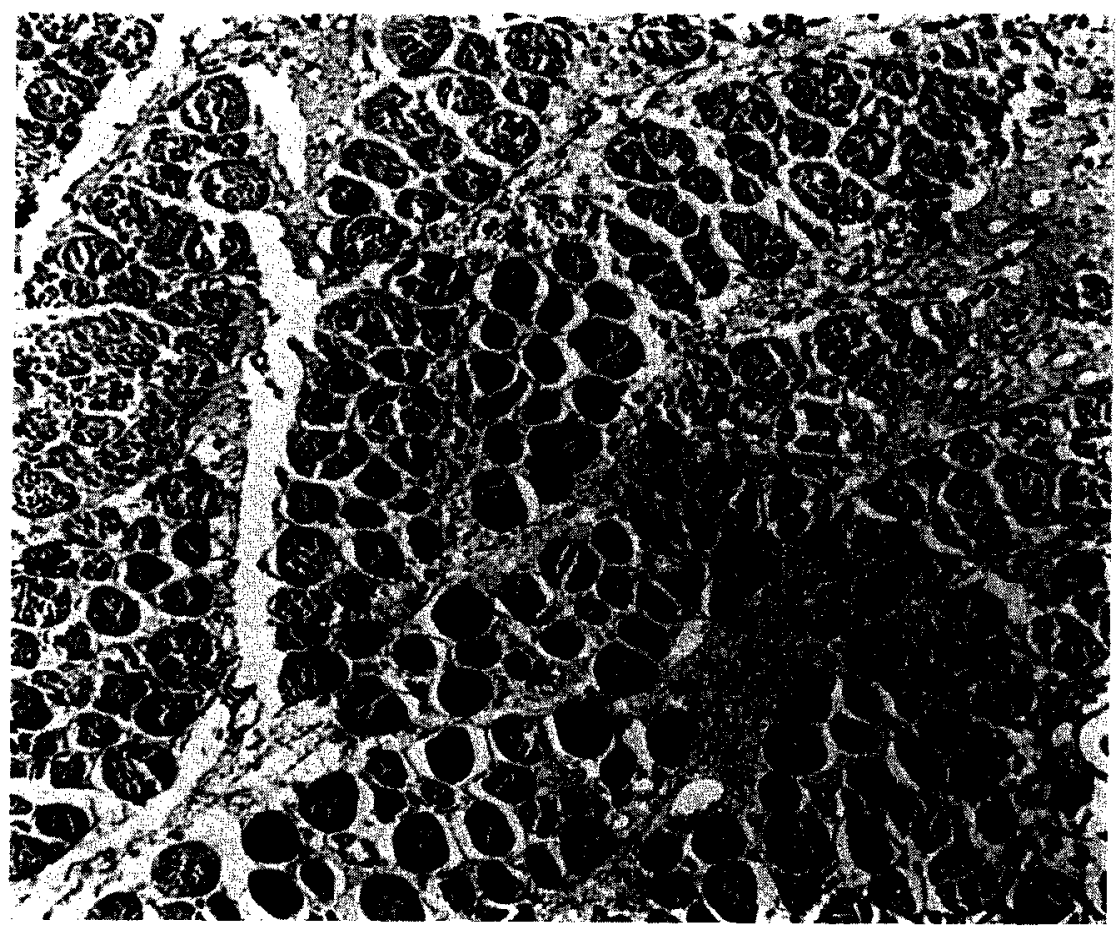

FIG. 5. Higher power view of central area of graft shown in Fig. 3. Old muscle fibers occupy the entire field. Marcaine-treated grafts show a greater degree of sarcoplasmic fragmentation beforc becoming invaded by macrophages than do muscle fibers in normal or predenervated grafts. Hematoxylin and eosin. $\times 143$. 


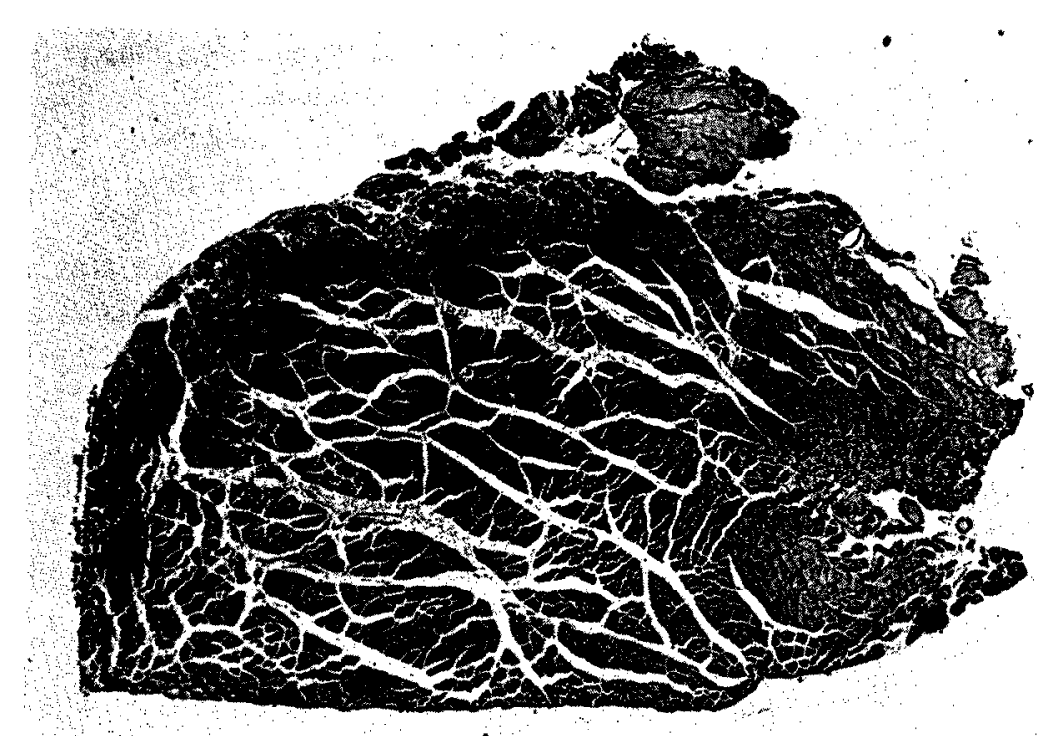

FIG. 6. Sixty-day graft of muscle given two preinjections of Marcaine. This section contained 4374 muscle fibers. Hematoxylin and eosin. $\times 33$.

inward expansion of the middle zone and the initiation of regenerative changes on its expanding edge, a radial gradient of regeneration is set up as it has been described in a minced muscle (3). In the rat, only occasional surviving muscle fibers have been found in the middle zone of predenervated grafts. This is in apparent contrast to the situation in free grafts of cat muscle (14).

The Marcaine treatment used here eliminated essentially all the original muscle fibers from the graft. There was no substantial difference between the results obtained with two injections as opposed to only one injection at the time of grafting (Table 1 ). The inability to produce complete degeneration of muscle fibers in the nongrafted extensor digitorum longus that has been injected with Marcaine plus hyaluronidase is difficult to explain because in some preliminary groups the same injection technique as that used by Hall-Craggs (10) was followed. However, the Marcaine used in this study was from a different source, and it has been shown that the myotoxicity of different forms of Marcaine differs (12). In addition, Hall-Craggs (10) worked with the tibialis anterior muscle of the rat. Despite the fact that the extensor digitorum longus muscles were injected under direct surgical exposure and were thus known to have been saturated with Marcaine solution, experience in other areas has shown that one cannot expect identical results when the same treatment is applied to two different muscles in the rat, even though the muscles appear to be quite siminilar, 
The pattern of degeneration in nontransplanted, Marcaine-injected extensor digitorum longus muscles showed most of the degeneration in the central part of the muscle and considerable survival of peripheral muscle fibers, which are the only ones that survive in grafts (Carlson, unpublished data). Because of this pattern of degeneration, injection plus soaking the muscle in Marcaine solution for 10 min was adopted to produce maximum damage to peripheral muscle fibers. Out of many procedures that were attempted, this provided the best results. To date, Marcaine-treated extensor digitorum longus grafts have provided the most satisfactory experimental model for studying the contractile properties of a pure population of regenerating muscle fibers ( 7 ).

In each of the four experimental groups, the numbers of muscle fibers in long-term grafts were not significantly different from the number of muscle fibers in the normal extensor digitorum longus, despite the wide variation in the number of surviving muscle fibers in the individual groups. Although they possessed normal numbers of muscle fibers, the grafts were considerably thinner than the normal extensor digitorum longus muscle and their contractile strength was always less $(6,7)$. The main reason for this is the presence of fascicles of very thin muscle fibers within the grafts. A likely explanation is a deficiency of innervation to certain areas of the grafts, but direct evidence of this has not yet been obtained.

These results demonstrate that although in some cases (primarily after predenervation), there are substantial numbers of surviving muscle fibers in small muscle grafts, there is no correlation between the number of surviving muscle fibers and the number of muscle fibers in 60-day grafts. This leads to the conclusion that in a free muscle graft, any deficiency created by the degeneration of original muscle fibers is made up by the regeneration of new muscle fibers. Because in the free grafting model the connective tissue architecture of the muscle and even the basement membranes of the degenerated muscle fibers remain largely intact, the results of this paper suggest an almost one-to-one ratio of replacement of old muscle fibers by new ones forming within the basement membranes of the old one. This conclusion is supported by the results of Bishoff (1) and Koningsberg et al. (13), who have observed this phenomenon in single mature muscle fibers cultured in vitro.

In conclusion, the regeneration of new muscle fibers, rather than the survival of old muscle fibers appears to be the major factor accounting for the success of frec muscle grafts in the rat.

\section{REFERENCES}

1. Bısснин, R. 1975. Regeneration of single skeletal muscle fibers in vitro. Anat. Rec, 182 : 215-236.

2. Bosova, N. N. 1962. Free autoplastic transplantation of whole muscles (in Russian). Byull. Exp. Biol. Med. 53(3) : 88-92. 
3. Carlson, B. M. 1972. "The Regeneration of Minced Muscles, Monographs in Developmental Biology," Vol. 4. S. Karger, Basel.

4. Carlson, B. M. 1973. The regeneration of skeletal muscle-a review. Amer. $J$. Anat. 137: 119-150.

5. Carlson, B. M., and E. Gutmann. 1975. Regeneration in free grafts of normal and denervated muscles in the rat: Morphology and histochemistry. Anat. Rec. 183: 47-62.

6. Carlson, B. M., and E. Gutmann. 1975. Regeneration in grafts of normal and denervated rat muscles: Contractile properties. Pfiügers Arch. 353 : 215-225.

7. Carlson, B. M., and E. Gutmann. 1976. The free grafting of the extensor digitorum longus muscle in the rat after Marcaine pre-treatment. Exp. Neurol. In press.

8. Hakelius, L. 1974. Free autogenous transplantation of striated muscle. Dissertation Abstract No. 196 from University of Uppsala, Faculty of Medicine.

9. Hakelius, L., B. Nyström, and E. STÅlberg. 1975. Histozhemical and neurophysiological studies of autotransplanted cat muscle. Scand. J. Plast. Reconstr. Surg. 9: 15-24.

10. Hall-Craggs, E. C. B. 1974. Rapid degeneration and regeneration of a whole skeletal mus:le following treatment with bupivacaine (Marcaine). Exp. Neurol. 43 : 349-358.

11. Hall-Craggs, E. C. B., and H. Singh-Seyan. 1975. Histochemical changes in innervated and denervated skeletal muscle fibers following treatment with bupivacaine (Marcaine). Exp. Neurol. 46: 345-354.

12. JiRmanoví, I., and S. TheslefF. 1972. Ultrastructural study of experimental muscle degeneration and regeneration in the adult rat. $Z$. Zellforsch. 131: 77-97.

13. Koningsberg, U. R., B. H. Lipton, and I. R. Koningsberg. 1975. The regenerative response of single mature muscle fibers isolated in vitro. Devel. Biol. 45 : 260-275.

14. Schiaffino, S., M. Sjöström, L. E. Thorneld, B. Nyström, and L. Hakelius. 1975. The process of survival of denervated and freely autotransplanted skeletal muscle. Experientia 31 : 1328-1330.

15. Stunirsky, A. N., and N. N. Bosova. 1960. Development of atrophic muscular tissue in conditions of transplantation in place of mechanically damaged muscles (in Russian). Arkh. Anat. Gist. Embriol. 39(12): 18-32.

16. Thompson, N. 1971. Autogenous free grafts of skeletal muscle. Plastic Reconstr. Surg. $48: 11-27$.

17. ThOMPSON, N. 1971. Investigation of autogenous skeletal muscle free grafts in the dog. Transplantation $12: 353-363$.

18. Thompson, N. 1974. A review of autogenous skeletal musclc grafts and their clinical applications. Clinics in Plastic Surg. 1 : 349-403.

19. Vyskočıl, F., B. Carlson, and E. Gutmann. 1973. Changes in resting membrane potential and contractility of innervated and denervated skeletal muscle free grafts in the rat. Pfiugers Arch. 344 : 181-186.

20. Zhenevskaya, R. P. 1968. Transplantation of skeletal muscle in animals (in Russian). Uspech. Sovrem. Biol. 65 : 133-143.

21. Zhenevskaya, K. P., O. N. Rumyantsev, I. V. Novoselova, and E. V. Proshlyakova. 1965. Regenerative processes in a transplant of tuntreated muscle of young rats (in Russian). Zhur. Obsch. Biol. 26: 569-576. 